\title{
Numerical simulations of atmospheric waves excited by the 2011 off the Pacific coast of Tohoku Earthquake
}

\author{
M. Matsumura ${ }^{1}$, A. Saito ${ }^{1}$, T. Iyemori ${ }^{2}$, H. Shinagawa ${ }^{3}$, T. Tsugawa ${ }^{3}$, Y. Otsuka ${ }^{4}$, M. Nishioka ${ }^{4}$, and C. H. Chen ${ }^{1}$ \\ ${ }^{1}$ Graduate School of Science, Kyoto University, Kyoto, Japan \\ ${ }^{2}$ Data Analysis Center for Geomagnetism and Space Magnetism, Kyoto University, Japan \\ ${ }^{3}$ National Institute of Information and Communications Technology, Koganei, Tokyo 184-8795, Japan \\ ${ }^{4}$ Solar-Terrestrial Environment Laboratory, Nagoya University, Nagoya, Japan
}

(Received April 10, 2011; Revised July 21, 2011; Accepted July 23, 2011; Online published September 27, 2011)

\begin{abstract}
Numerical simulations are performed to simulate atmospheric perturbations observed at ionospheric heights just after the 2011 off the Pacific coast of Tohoku Earthquake. A time-dependent, two-dimensional, nonlinear, non-hydrostatic, compressible and neutral, numerical model is developed to reproduce the atmospheric perturbations. An impulsive upward surface motion is assumed as the source of the perturbations. Simulated atmospheric perturbations at 300-km altitude show remarkable agreement with oscillations observed in the ionospheric total electron content (TEC) when the source width is about $250 \mathrm{~km}$. In the vicinity of the source, the acoustic resonance modes between the ground surface and the lower thermosphere are dominant. They have three dominant frequencies for the interval between 20 and 60 min after the impulsive input. The perturbation with the maximum amplitude has a frequency of $4.4 \mathrm{mHz}$. The other dominant modes have frequencies of 3.6 and $5.1 \mathrm{mHz}$. The beats between the dominant modes are also seen. In the distance, the gravity modes are dominant. The horizontal phase velocities are about 220 to $300 \mathrm{~m} / \mathrm{s}$, and the horizontal wavelengths are about 200 to $400 \mathrm{~km}$. The good agreement between the simulation and the observations indicates that ionospheric oscillations generated by the earthquake are mainly due to the motion of the neutral atmosphere.
\end{abstract}

Key words: Acoustic wave, acoustic resonance, gravity wave, TEC, earthquake.

\section{Introduction}

Acoustic waves with low frequencies close to the cutoff frequency can be trapped between some altitudes due to the thermal structure of the atmosphere. Theoretical and numerical studies have shown that atmospheric waves with frequencies around the acoustic cutoff can be trapped between the ground surface and the lower thermosphere. Modal resonance occurs at frequencies of about 3.7 and $4.5 \mathrm{mHz}$ although some part of the energy leaks upward (Jones and Georges, 1976; Lognonné et al., 1998; Kobayashi, 2007; Shinagawa et al., 2007; Watada and Kanamori, 2010).

The upward leakage of the atmospheric oscillations was observed at the ionospheric height. Dautermann et al. (2009) reported a double train of wave-packets of total electron content (TEC) which resulted from the beats of the dominant atmospheric modes around $4 \mathrm{mHz}$ after the 2003 July 13, Soufriére Hills Volcano explosion (Montserrat, Lesser Antilles). Choosakul et al. (2009) reported a periodic fluctuation of TEC measured by GPS receivers after the Sumatra 2004 earthquake. 4-min (4-mHz) periodic TEC variations continued for more than four hours near the epicenter. They were observed by only three GPS stations whose distance from the epicenter was less than $1200 \mathrm{~km}$.

Copyright (C) The Society of Geomagnetism and Earth, Planetary and Space Sciences (SGEPSS); The Seismological Society of Japan; The Volcanological Society of Japan; The Geodetic Society of Japan; The Japanese Society for Planetary Sciences; TERRAPUB.

doi:10.5047/eps.2011.07.015
Since this observation was carried out by several stations the two-dimensional structures of the ionospheric variations generated by the acoustic resonance were not detected.

After the $M 9.0$ Tohoku Earthquake (epicenter: $38.32^{\circ} \mathrm{N}$, $142.36^{\circ} \mathrm{E}$, origin time: 05:46:23 UT on March 11, 2011 (US Geological Survey)), two-dimensional structures of periodic oscillations of TEC were observed by a dense GPS receiver network (Chen et al., 2011; Saito et al., 2011; Tsugawa et al., 2011). The TEC oscillations had circular or concentric structures. The center of the structures was closer to the Japan trench than the epicenter (Tsugawa et al., 2011). This was consistent with the source of the largest tsunami estimated from tsunami waveform inversion (Fujii et al., 2011). This indicates that the atmospheric waves were generated by a displacement of the sea surface caused by the earthquake, and propagated upward to the thermosphere (Saito et al., 2011; Tsugawa et al., 2011). In the vicinity of the epicenter, two-dimensional structures of the ionospheric variations generated by the acoustic resonance between the ground surface and the lower thermosphere was firstly observed (Saito et al., 2011). The area of the acoustic resonance may correspond to that of the sea-surface displacement. This means that the area and the amplitude of the sea-surface displacement can be estimated from those of the observed TEC oscillations. It is necessary for the estimation to simulate the structures of the oscillations qualitatively and quantitatively. In this study, as a first step for the estimation, we simulate qualitatively the neutral atmospheric perturbations at the ionospheric heights. 


\section{Model}

In this study, a time-dependent, two-dimensional, nonlinear, non-hydrostatic, compressible, neutral, numerical model is used. The model is a subset of the model by Shinagawa et al. (2007) for the neutral atmosphere. The basic equations of the model are the continuity and momentum equations for the horizontal and vertical directions, the energy equation, and the equation of state of an ideal gas, as follows:

$$
\begin{aligned}
\frac{\partial \rho}{\partial t} & =-(\vec{u} \cdot \nabla) \rho-\rho(\nabla \cdot \vec{u}), \\
\frac{\partial u}{\partial t} & =-(\vec{u} \cdot \nabla) u-\frac{1}{\rho} \frac{\partial p}{\partial x}+\frac{1}{\rho} \nabla \cdot(\eta \nabla u), \\
\frac{\partial w}{\partial t} & =-(\vec{u} \cdot \nabla) w-\frac{1}{\rho} \frac{\partial p}{\partial z}-g+\frac{1}{\rho} \nabla \cdot(\eta \nabla w), \\
\frac{\partial T}{\partial t} & =-(\vec{u} \cdot \nabla) T-\frac{R T}{c_{\mathrm{v}}}(\nabla \cdot \vec{u})+\frac{1}{\rho c_{\mathrm{v}}} \frac{\partial}{\partial z}\left(\kappa \frac{\partial T}{\partial z}\right), \\
p & =\rho R T,
\end{aligned}
$$

where $t$ denotes time, $x$ horizontal (longitudinal) distance, $z$ altitude, $\rho$ mass density, $\vec{u}$ velocity vector, $u$ horizontal velocity, $w$ vertical velocity, $p$ pressure, $g$ gravitational acceleration, $R$ gas constant, $T$ temperature, $c_{\mathrm{v}}$ specific heat at constant volume, $\eta$ molecular viscosity and $\kappa$ thermal conduction coefficient. The eddy diffusion for viscosity and heat conduction is not considered here. The Coriolis force in the momentum equations is also neglected because the frequency of the Earth's rotation, $1 / 24 \mathrm{~h} \sim 0.012 \mathrm{mHz}$, is much lower than that of waves of interest here, i.e. 1 to $6 \mathrm{mHz}$. The cubic-interpolated pseudo-particle (CIP) method (Yabe et al., 1991) is used to calculate advection terms. The basic state of the atmosphere is taken from the empirical model, NRLMSISE-00 (Picone et al., 2002). The atmospheric density and temperature are set to the condition for 1500 LT (local time) on March 11, and a latitude and longitude of $38.0^{\circ} \mathrm{N}$ and $143.0^{\circ} \mathrm{E}$, respectively. The $F_{10.7 \mathrm{~cm}}$ value (the index of solar extreme ultraviolet flux) is set to be 121 . The index for magnetic activity, $A_{\mathrm{p}}$, is taken to be 37. Our model does not include the background wind field. The vertical background wind is generally small enough to be negligible in the case of both acoustic and gravity waves.

The horizontal background wind should affect the propagation of gravity waves by altering the intrinsic wave frequency (Kato, 1980). For the acoustic waves around the cutoff frequency, however, the background wind is not very important since the horizontal phase velocity of the acoustic waves is much larger than the background wind velocity. Here, we focus on the structure of the acoustic waves, so the background wind is neglected.

The altitude range in the model is from $0 \mathrm{~km}$ (the surface) to $350 \mathrm{~km}$, and the horizontal range is $-1800 \mathrm{~km}$ to $1800 \mathrm{~km}$. The horizontal and vertical grid spacings are 4 and $1 \mathrm{~km}$, respectively. The time step used is $0.1 \mathrm{~s}$. Sponge layers are applied above $350 \mathrm{~km}$ up to $\pm 1800 \mathrm{~km}$ to prevent spurious wave reflections. The sponge layers contain 50 levels. The source of the atmospheric perturbations is created by assigning a vertical velocity to the center of the lower boundary $(z=0)$ assuming an upward motion of the sea surface. The vertical velocity at the surface is given as

$$
\begin{aligned}
& w(x, z=0, t)=w_{0}(t) \exp \left(-x^{4} / \sigma_{x}^{4}\right), \\
& w_{0}(t)=\frac{w_{\text {in }}}{2}\left(1-\cos \left(2 \pi \frac{t}{T_{\text {in }}}\right)\right)(t \leq 50 \mathrm{~s}),
\end{aligned}
$$

where $\sigma_{x}=125 \mathrm{~km}, w_{\text {in }}=0.50 \mathrm{~cm} / \mathrm{s}, T_{\text {in }}=50 \mathrm{~s}$. The time scale of the source displacement assumed here $\left(T_{\text {in }}\right)$ is rather arbitrary, but our test calculations suggest that as long as the displacement is fast enough to generate acoustic waves, the effect on the thermosphere is approximately the same. The lower boundary conditions are given as follows: (1) For mass density, linear extrapolation from the values at the adjacent upper grid points, (2) For vertical velocity, fixed (zero), (3) For horizontal velocity, symmetric (the same value as the one at the adjacent upper grid point), (4) For temperature, linear extrapolation from the values at the adjacent upper grid points.

\section{Results and Discussion}

Figure 1 shows the observed TEC oscillations from 05:46 to $07: 46 \mathrm{UT}$ at $37.5^{\circ} \mathrm{N}$, the same latitude as the ionospheric epicenter (see Tsugawa et al., 2011 for details). The TEC data are detrended with a 10-min running average. There are two remarkable structures. One involves waves with high frequency above the epicenter region. The other involves waves which reach a distant region from the source. The latter in Fig. 1 have horizontal phase velocities of about $220 \mathrm{~m} / \mathrm{s}$ on the line "A", $240 \mathrm{~m} / \mathrm{s}$ on "B", $290 \mathrm{~m} / \mathrm{s}$ on "C", $420 \mathrm{~m} / \mathrm{s}$ on "D", $780 \mathrm{~m} / \mathrm{s}$ on "E" and $3500 \mathrm{~m} / \mathrm{s}$ on "F".

Figure 2 shows the simulated density perturbations at an altitude of $300 \mathrm{~km}$ as a function of time and horizontal distance $(x)$ from the center of the source. The present simulation reproduces these structures quite well except for the first and second large-scale waves with propagation velocities of $3,500 \mathrm{~m} / \mathrm{s}$ and $780 \mathrm{~m} / \mathrm{s}$. The background mass density is $\sim 10^{-14} \mathrm{~g} / \mathrm{cm}^{3}$. So the fraction of the perturbations to the background is about $\sim 0.1 \%$ in this case.

The waves above the source have higher frequencies than those further away. Spectral analyses are performed for these high-frequency perturbations. Power spectral densities (PSD) of density perturbations are calculated with the maximum-entropy method using 1 -s samples. PSD at $x=0 \mathrm{~km}$ between 20 and $60 \mathrm{~min}$ of the simulation time is shown in Fig. 3. The largest peak is seen at $4.4 \mathrm{mHz}$. There are two other large peaks at $5.1 \mathrm{mHz}$ and $3.6 \mathrm{mHz}$. This is consistent with the observed TEC oscillations reported by Saito et al. (2011). The frequencies show that these perturbations are acoustic modes. Frequencies of about $4 \mathrm{mHz}$ are close to the acoustic cutoff below 100-km altitude. It is known that near the acoustic cutoff frequency the acoustic modes with longer wavelengths have larger horizontal phase velocities and smaller horizontal group velocities (Watada and Kanamori, 2010). For example, the dominant acoustic modes with a wavelength of $1,300 \mathrm{~km}$ have horizontal phase velocities of 4 to $5 \mathrm{~km} / \mathrm{s}$, and a horizontal group velocity of about $10 \mathrm{~m} / \mathrm{s}$ below $200-\mathrm{km}$ altitude (Watada and Kanamori, 2010). Acoustic modes are limited in the vicinity of the source region due to these characteristics. Acoustic waves with frequencies around $4 \mathrm{mHz}$ can 


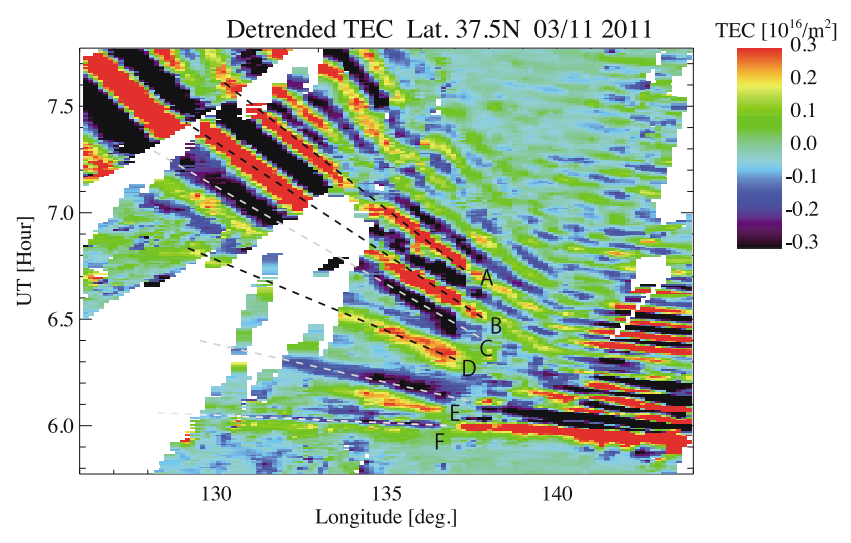

Fig. 1. Observed TEC oscillations along $37.5^{\circ} \mathrm{N}$ latitude from $126^{\circ} \mathrm{E}$ to $144^{\circ} \mathrm{E}$ from 05:46 UT to 07:46 UT. The waves which reach the distant region from the source have horizontal phase velocities of about 220 $\mathrm{m} / \mathrm{s}$ on the line "A", $240 \mathrm{~m} / \mathrm{s}$ on "B", $290 \mathrm{~m} / \mathrm{s}$ on "C", $420 \mathrm{~m} / \mathrm{s}$ on "D", $780 \mathrm{~m} / \mathrm{s}$ on "E" and $3500 \mathrm{~m} / \mathrm{s}$ on "F".

be trapped between the ground surface and the lower thermosphere. The three dominant frequencies seen in Fig. 3 correspond to the eigenfrequencies. Long-sustained perturbations show that acoustic waves are trapped. Perturbations seen at an altitude of $300 \mathrm{~km}$ are the leakage from the trapped region. The amplitude of the vertical velocity normalized by the square root of the background mass density above $100-\mathrm{km}$ altitude is smaller by a factor of $\sim 10$ than below $100 \mathrm{~km}$ (not shown here). So the percentage of the leakage of the kinetic energy is $\sim 1 \%$. It is seen that perturbations above the source region form packet structures with a period of about $25 \mathrm{~min}$ (frequency of about $0.7 \mathrm{mHz}$ ) in Fig. 2. The packet structures can be formed by the beats between the dominant modes. The amplitude of the mode of $5.1 \mathrm{mHz}$ decreases more rapidly with time than that of the other two modes. The peak of this mode is not seen between 60 and 100 min as shown in Fig. 4 (red line). The other two modes, $4.4 \mathrm{mHz}$ and $3.6 \mathrm{mHz}$, continue for more than two hours. This means that the long-sustained beats are formed by them. The frequency of the beats is the difference of the two dominant frequencies, $0.8 \mathrm{mHz}$. This is consistent with the frequency of the packet structures. This mechanism was proposed by Dautermann et al. (2009). PSDs at $x=0,400$, 800,1200 and $1600 \mathrm{~km}$ and at $z=300 \mathrm{~km}$ between 60 and $100 \mathrm{~min}$ are shown in Fig. 4. As the distance from the source increases, the amplitudes of perturbations between the frequencies of 3 and $6 \mathrm{mHz}$ decrease.

Further out than $800 \mathrm{~km}$, waves in the simulation have horizontal phase velocities of about $220 \mathrm{~m} / \mathrm{s}$ on the line "a", $250 \mathrm{~m} / \mathrm{s}$ on "b" and $300 \mathrm{~m} / \mathrm{s}$ on "c", and horizontal wavelengths of about $200 \mathrm{~km}$ on "a" and $400 \mathrm{~km}$ on "c" as shown in Fig. 2. These are in good agreement with the observational results (A to $\mathrm{C}$ ) shown in Fig. 1. Both figures show that waves in the distance with longer horizontal wavelengths have a larger horizontal phase velocity at a certain time. Figure 4 shows that the frequency of the waves becomes lower according to the distance from the epicenter. They are the features of the gravity modes (e.g., Kato, 1980). The amplitudes of lower frequencies below $2 \mathrm{mHz}$ increases as the distance from the source increases as shown

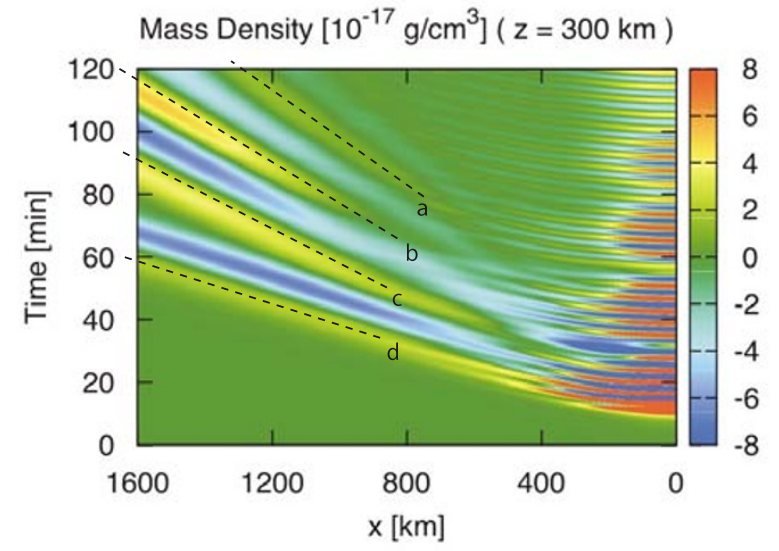

Fig. 2. Simulated mass-density perturbations at the altitude $(z)$ of $300 \mathrm{~km}$ as a function of time and horizontal distance from the center of the source $(x)$. Up to $800 \mathrm{~km}$, waves have horizontal phase velocities of about $220 \mathrm{~m} / \mathrm{s}$ on the line "a", $250 \mathrm{~m} / \mathrm{s}$ on "b", $300 \mathrm{~m} / \mathrm{s}$ on "c" and $490 \mathrm{~m} / \mathrm{s}$ on "d", and horizontal wavelengths of about $200 \mathrm{~km}$ on "a" and $400 \mathrm{~km}$ on "c".

in Fig. 4. This indicates that gravity waves with higher frequencies are close to evanescent below $300 \mathrm{~km}$ altitude.

The noticeable discrepancy between the simulation and the observational results is the existence of the fast propagating waves with velocities of 3,500 and $780 \mathrm{~m} / \mathrm{s}$ at early periods, from $05: 55$ to $06: 15$ UT in the observation. This could be caused by the assumption of the initial change in the atmospheric motion on the ground-surface as the source. In the simulation, the source is only applied from $-125 \mathrm{~km}$ to $125 \mathrm{~km}$ at time 0 . In the actual situation, seismic waves such as Rayleigh waves can also be the source of the atmospheric waves.

A wave with a phase velocity of $490 \mathrm{~m} / \mathrm{s}$ on " $\mathrm{d}$ " in Fig. 2 is a longitudinal wave propagating purely horizontally with a vertical wavefront above $100-\mathrm{km}$ altitude (not shown here). The sound speed at $300-\mathrm{km}$ altitude in the atmosphere used in the simulation is about $640 \mathrm{~m} / \mathrm{s}$. Therefore, this wave is neither a gravity wave nor an acoustic wave. A wave with a phase velocity of $420 \mathrm{~m} / \mathrm{s}$ on " $D$ " in Fig. 1 might be the different mode from " $A$ " to " $C$ " because it decreases more rapidly than the three modes. Further analyses are necessary to determine what mode " $d$ " and "D" belong to.

Another calculation is performed with a source width of $1000 \mathrm{~km}(-500 \mathrm{~km}$ to $500 \mathrm{~km})$ as shown in Fig. 5. The area of the acoustic resonance expands up to $x=800 \mathrm{~km}$ while it is about $x=300 \mathrm{~km}$ for the narrow source width. The result of the calculation with a width of $250 \mathrm{~km}$ reproduces the observational results better, especially the region of the acoustic resonance. The observational result shown in Fig. 1 shows that the acoustic resonance region has a sharp edge at the longitude of $141^{\circ} \mathrm{E}$, about $300 \mathrm{~km}$ away from the center of the resonance region between 30 and $50 \mathrm{~min}$ after the earthquake. The simulated acoustic resonance region also has a sharp edge at $x=300 \mathrm{~km}$ for a source width of $250 \mathrm{~km}$ between 30 and $50 \mathrm{~min}$ of the simulation time. However, the edge is broader i.e., the resonance region is smaller and the amplitudes of acoustic waves propagating horizontally are larger, for a source 


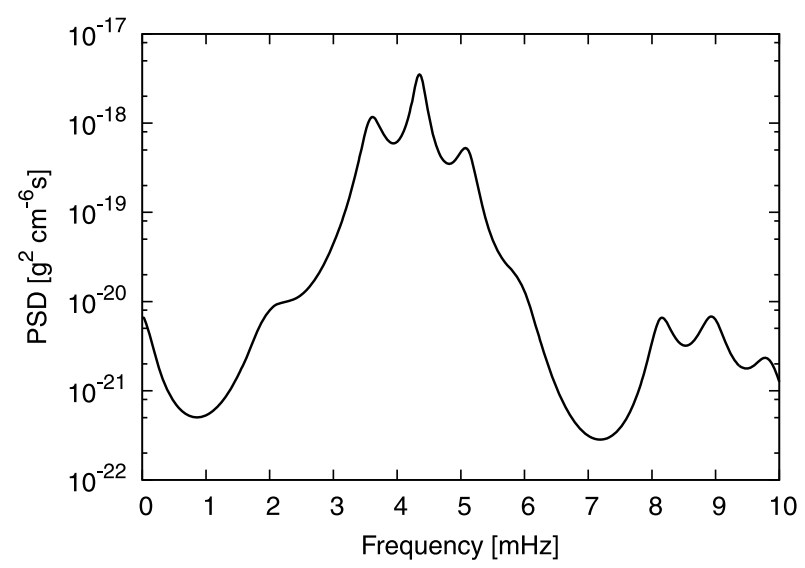

Fig. 3. Power spectral density (PSD) of density perturbations at an altitude of $300 \mathrm{~km}$ directly over the source between times of 20 and $60 \mathrm{~min}$ of the simulation.

width smaller than $250 \mathrm{~km}$ (simulated but not shown). This suggests that $250 \mathrm{~km}$ is the optimum source width to simulate the observed oscillations.

Another simulation is performed with a source amplitude $\left(w_{\text {in }}\right)$ of $5.0 \times 10^{-3} \mathrm{~cm} / \mathrm{s}$ (but not shown). The fraction of the atmospheric perturbations to the background at $300-\mathrm{km}$ altitude is about $\sim 0.001 \%$ in this case. Both the source amplitude and the amplitudes of upper atmospheric perturbations are smaller by a factor of 100 than for the source amplitude of $0.50 \mathrm{~cm} / \mathrm{s}$. The features of the upper atmospheric perturbations are not so different qualitatively from those with the larger source amplitude. This shows that the response of the amplitudes of upper atmospheric perturbations is linear to the source amplitude. Therefore, the source amplitude can be estimated if the amplitudes of upper atmospheric perturbations are obtained by observation.

Most of the features of periodic TEC oscillations can be explained qualitatively with only neutral atmospheric perturbations although the source is assumed to be a fairly simple surface displacement. In several previous studies, it was reported that gravity waves generated by tsunamis were detected in the ionospheric TEC (e.g., Rolland et al., 2010). Our simulation, however, indicates that the dominant atmospheric oscillations observed in the ionospheric TEC near the epicenter were generated by a sea-surface displacement, not by a propagating tsunami.

It is necessary for the estimation of a more realistic source to consider ionospheric plasma motions and reproduce observational results quantitatively. If the surface displacement which generates a tsunami is estimated, the height of a tsunami can be estimated with a general tsunami simulation.

\section{Conclusions}

Numerical simulations are performed to simulate the atmospheric perturbations observed at ionospheric heights just after the 2011 off the Pacific coast of Tohoku Earthquake. The oscillations of TEC observed with a GPS receiver array had high frequencies near the epicenter and low frequencies in the distance. The dominant frequencies near the epicenter indicated that the acoustic resonance between

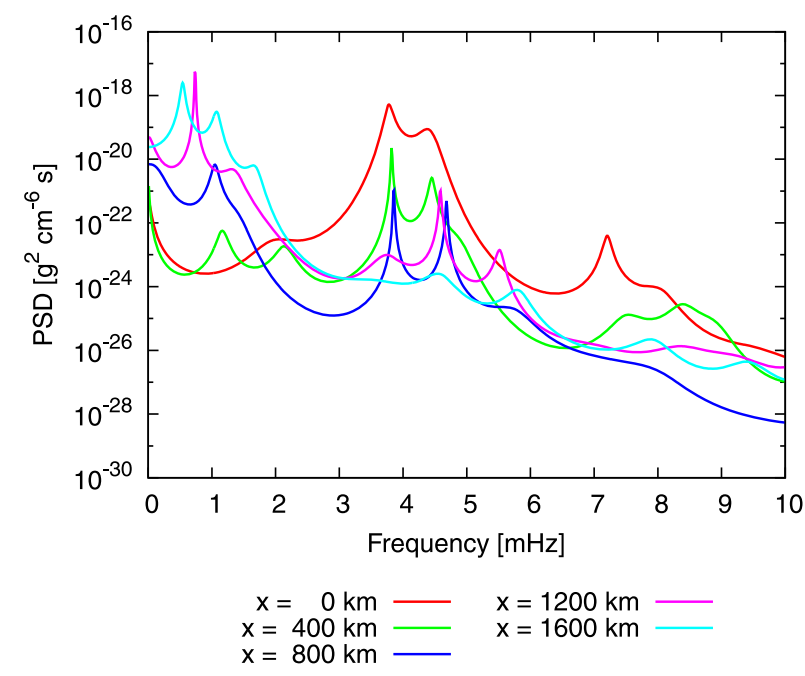

Fig. 4. Power spectral density (PSD) of density perturbations at an altitude of $300 \mathrm{~km}$ at $x=0,400,800,1200,1600 \mathrm{~km}$ between times of 60 and $100 \mathrm{~min}$ of the simulation.

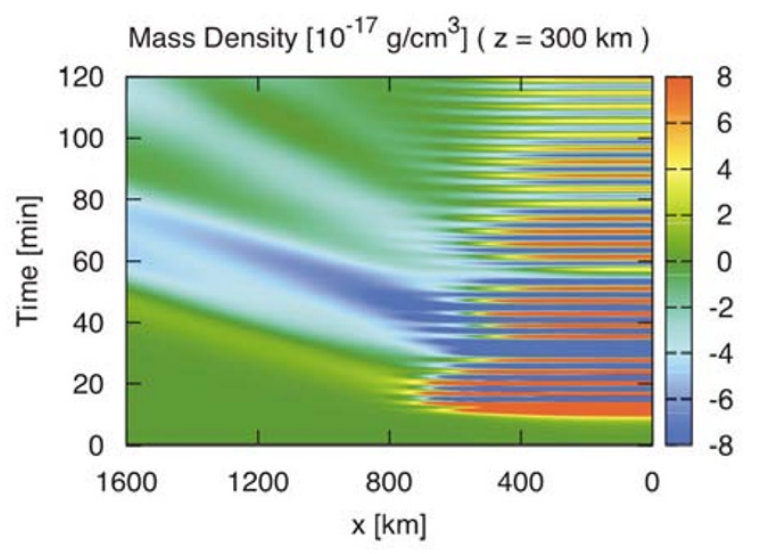

Fig. 5. Same figure as Fig. 2 except the source range of $x=-500 \mathrm{~km}$ to $500 \mathrm{~km}$.

the ground-surface and the lower-thermosphere was excited by the earthquake. Simulated atmospheric perturbations at $300-\mathrm{km}$ altitude show remarkable agreement with the observed TEC oscillations qualitatively, although the background wind is neglected. The good agreement indicates that ionospheric oscillations generated by the earthquake are mainly due to the motion of the neutral atmosphere. The area and the amplitude of the initial sea surface displacement which generate a tsunami might be estimated by considering ionospheric plasma motions and simulating observational results quantitatively.

Acknowledgments. This work was supported by Grant-in-Aid for JSPS Fellows. In this research work we used the supercomputer of ACCMS, Kyoto University. The GPS data of GEONET was provided by Geophysical Information Authority, Japan.

\section{References}

Chen, C. H., A. Saito, C. H. Lin, J. Y. Liu, H. F. Tsai, T. Tsugawa, Y, Otsuka, M. Nishioka, and M. Matsumura, Long-distance propagation of ionospheric disturbance generated by the 2011 off the Pacific coast of Tohoku Earthquake, Earth Planets Space, 63, this issue, 881-884, 2011. 
Choosakul, N., A. Saito, T. Iyemori, and M. Hashizume, Excitation of 4-min periodic ionospheric variations following the great Sumatra-Andaman earthquake in 2004, J. Geophys. Res., 114, A10313, doi:10.1029/2008JA013915, 2009.

Dautermann, T., E. Calais, P. Lognonné, and G. S. Mattioli, Lithosphereatmosphere-ionosphere coupling after the 2003 explosive eruption of the Soufriere Hills Volcano, Montserrat, Geophys. J. Int., 179, 15371546, doi:10.1111/j.1365-246X.2009.04390.x, 2009.

Fujii, Y., K. Satake, S. Sakai, M. Shinohara, and T. Kanazawa, Tsunami source of the 2011 off the Pacific coast of Tohoku Earthquake, Earth Planets Space, 63, this issue, 815-820, 2011.

Jones, R. M. and T. M. Georges, Infrasound from convective storms. III. Propagation to the ionosphere, J. Acoust. Soc. Am., 59, 765-779, 1976.

Kato, S., Chapter 2: Acoustic gravity waves (AGW's), in Dynamics of the Upper Atmosphere, edited by T. Rikitake, 233 pp, D. Reidel Publishing Company, 1980.

Kobayashi, N., A new method to calculate normal modes, Geophys. J. Int., 168, 315-331, doi:10.1111/j.1365-246X.2006.03220.x, 2007.

Lognonné, P., E. Clévédé, and H. Kanamori, Computation of seismograms and atmospheric oscillations by normal-mode summation for a spherical earth model with realistic atmosphere, Geophys. J. Int., 135, 388-406, 1998.

Picone, J. M., A. E., Hedin, D. P. Drob, and A. C. Aikin, NRLMSISE-00 empirical model of the atmosphere: Statistical comparisons and scientific issues, J. Geophys. Res., 107(A12), 1468, doi:10.1029/2002JA009430, 2002.

Rolland, L. M., G. Occhipinti, P. Lognonné, and A. Loevenbruck, Ionospheric gravity waves detected offshore Hawaii after tsunamis, Geo- phys. Res. Lett., 37, L17101, doi:10.1029/2010GL044479, 2010.

Saito, A., T. Tsugawa, Y. Otsuka, M. Nishioka, T. Iyemori, M. Matsumura, S. Saito, C. H. Chen, Y. Goi, and N. Choosakul, Acoustic resonance and plasma depletion detected by GPS total electron content observation after the 2011 off the Pacific coast of Tohoku Earthquake, Earth Planets Space, 63, this issue, 863-867, 2011.

Shinagawa, H., T. Iyemori, S. Saito, and T. Maruyama, A numerical simulation of ionospheric and atmospheric variations associated with the Sumatra earthquake on December 26, 2004, Earth Planets Space, 59, 1015-1026, 2007.

Tsugawa, T., A. Saito, Y. Otsuka, M. Nishioka, T. Maruyama, H. Kato, T. Nagatsuma, and K. T. Murata, Ionospheric disturbances detected by GPS total electron content observation after the 2011 off the Pacific coast of Tohoku Earthquake, Earth Planets Space, 63, this issue, 875879, 2011.

U.S. Geological Survey, http://earthquake.usgs.gov/, 2011.

Yabe, T., T. Ishikawa, P. Y. Wang, T. Aoki, Y. Kadota, and F. Ikeda, A universal solver for hyperbolic equations by cubic-polynomial interpolation II. Two- and three-dimensional solvers, Comput. Phys. Commun., 66, 233-242, 1991.

Watada, S. and H. Kanamori, Acoustic resonant oscillations between the atmosphere and the solid earth during the $1991 \mathrm{Mt}$. Pinatubo eruption, J. Geophys. Res., 115, B12319, doi:10.1029/2010JB007747, 2010.

M. Matsumura (e-mail: mitsuru@kugi.kyoto-u.ac.jp), A. Saito, T. Iyemori, H. Shinagawa, T. Tsugawa, Y. Otsuka, M. Nishioka, and C. H. Chen 